\title{
ISÓTOPOS ESTÁVEIS COMO UMA FERRAMENTA PARA ANÁLISE DA CONECTIVIDADE E CONSERVAÇÃO DE AMBIENTES NA BAÍA DE TODOS OS SANTOS (BAHIA,BRASIL).
}

\author{
Elizabete Cristina Araújo Sampaio ${ }^{\mathbf{1}}$; Alexandre Clistenes de Alcântara Santos ${ }^{\mathbf{2}}$ \\ 1.Bolsista Probic/CNPq, Graduando em Bacharelado em Ciências Biológicas, Universidade Estadual de Feira de \\ Santana, e-mail: elizabetesampaiobio@gmail.com \\ 2.Orientador, Departamento de Biologia, Universidade Estadual de Feira de Santana, e-mail: \\ alexandreclistenes@gmail.com
}

PALAVRAS CHAVE: Alimentação; Polydactylus Virginicus; Análise Isotópica.

\section{INTRODUÇÃO}

A Ilha de Itaparica (Figura1), localizada entre as coordenadas $13^{\circ} 00 \mathrm{~S}$ e $38^{\circ} 40 \mathrm{~W}$, é a maior ilha da Baía de Todos os Santos (BTS) com uma extensão de $30 \mathrm{~km}$ e área de aproximadamente $270 \mathrm{~km} 2$. Esta Ilha está localizada na entrada da BTS, sendo delimitada a oeste pelo Canal de Itaparica, a nordeste pelo Canal de Itaparica-Salvador e a leste pelo Oceano Atlântico (Araújo 1984). Na face leste da Ilha de Itaparica são encontradas praias arenosas marinhas, as quais são protegidas por um cordão recifal localizado paralelamente à linha de costa, especialmente na região nordeste da Ilha. $\mathrm{Na}$ face oeste, o menor hidrodinamismo e a maior influência dos rios Paraguaçu e Jaguaripe, principalmente, formam condições estuarinas que favorecem a existência de grandes áreas de manguezais e praias estuarinas compostas por sedimentos de granulometria menor, quando comparadas às praias marinhas (BAHIATURSA 1997).

Polydactylus virginicus (Linnaeus,1758) (Figura 3), pertencente à família Polynemidae da ordem Perciformes (Nelson,1994), é conhecido como parati-barbudo (Menezes \& Fiqueiredo,1985; Fischer,1978) e ocorre desde Nova Jérsei até Necochea (Argentina). Conforme Lopes \& Oliveira-Silva (1998) a espécie alimenta-se de matéria orgânica digerida, crustáceos Decapoda e microcrustáceos.

A UEFS, através do Laboratório de Ictiologia vem desenvolvendo estudos de taxonomia e ecologia dos peixes da BTS. A ictiofauna oriunda da pesca experimental utilizada neste projeto vêm sendo estudada em aspectos biológicos e ecológicos pela equipe do Laboratório de Ictiologia da UEFS. Nestes arrastos, peixes da espécie Polydactylus virginicus vem apresentando grande abundância (Santos et al, 2015)

Desta forma, acreditamos que a alta abundância de peixes da espécie P. Virginicus na Baía de todos os Santos, a grande carência de informações técnicas-científicas de referência para a gestão da pesca na área em estudo, justificam a importância deste trabalho para a manutenção dos recursos pesqueiros representados, neste contexto.

Figura 1: Ilha de Itaparica

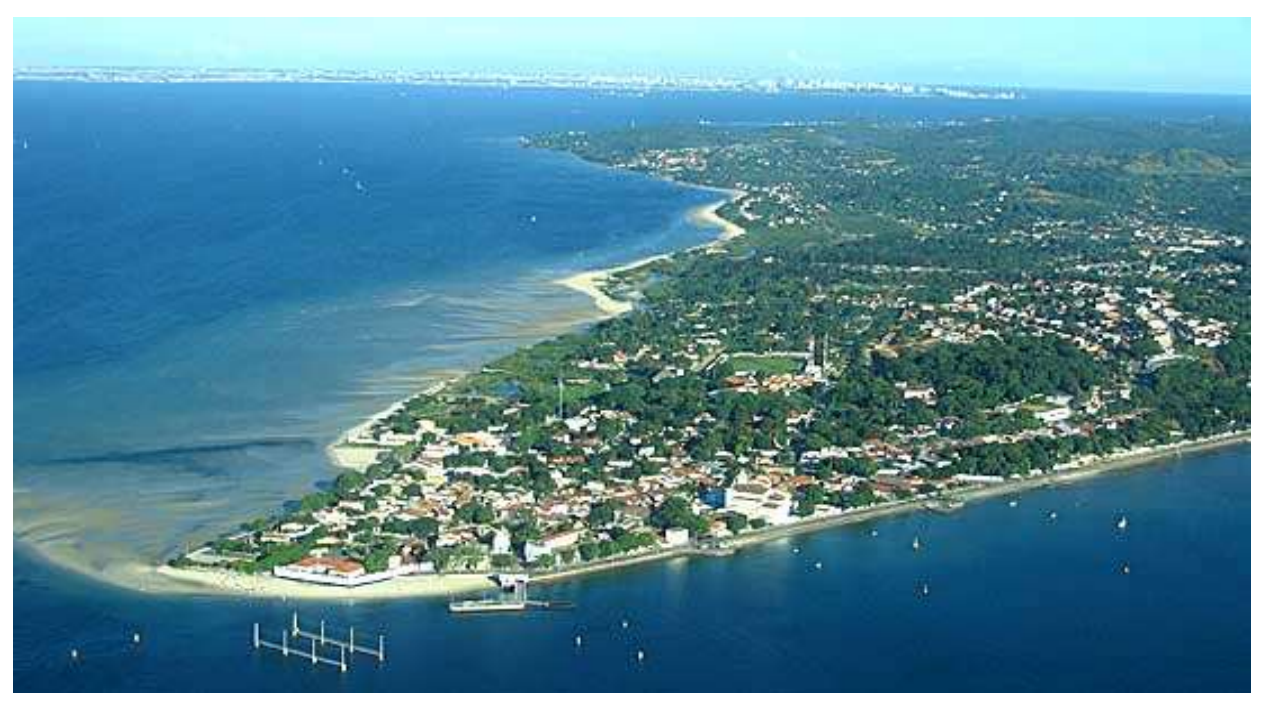




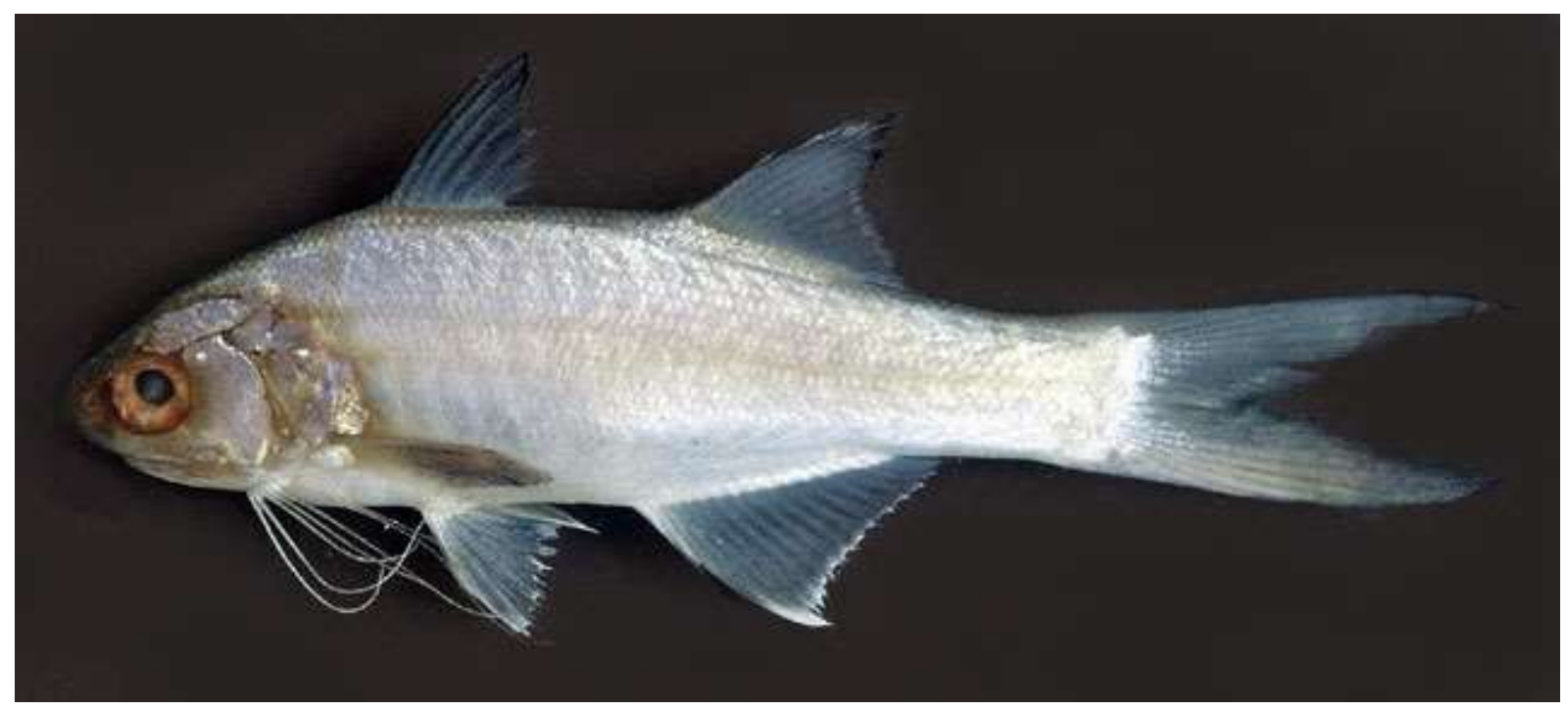

Figura 2: Polydactylus virginicus (Photo: Carvalho Filho,A)

\section{METODOLOGIA}

Amostragens mensais estão sendo realizadas em três estações amostrais da Ilha de Itaparica, estando duas delas localizadas na face leste da ilha, com forte influência marinha, e a terceira localizada na face oeste, com características predominantemente estuarinas. Em intervalos aproximados de três meses há um aumento no esforço amostral para a obtenção de amostras para Análises de Isótopos Estáveis (AIE). As amostragens das espécies no infralitoral da praia arenosa serão obtidas utilizando vários artefatos de coleta apropriados para cada grupo (e.g., rede de plâncton e rede de arrasto-manual do tipo picaré para amostragens do fitoplâncton e peixes, respectivamente). Todo material coletado é acondicionado em gelo e transferidos para o Laboratório de Ictiologia da Universidade Estadual. Posteriormente os organismos são triados e identificados ao menor nível taxonômico possível com bibliografia pertinente (Cervigón et al., 1992; Carvalho-Filho, 1999; FIGUEIREDO; MENEZES, 1978; MENEZES; FIGUEIREDO, 1980).

Para a caracterização da dieta, a análise dos itens do conteúdo estomacal será feita através do método volumétrico (HYNES, 1950; CORTÉS, 1997; HYSLOP, 198.Após a análise do conteúdo estomacal a espécie será classificada quanto ao grupo trófico de acordo com o item alimentar predominante. A análise quantitativa será feita através dos métodos de freqüência de ocorrência (FO\%) e volumétrico (VO\%) combinados no Índice Alimentar (IAi) (KAWAKAMI; VAZZOLER, 1980).

Em laboratório e após identificação, biometria e pesagem, os macro-consumidores serão dissecados para obtenção de tecido muscular para as análises isótópicas (AIEs). A posição trófica de Polydactylus virginicus será computada a partir das formulações sugeridas em Post (2002). A identificação e a quantificação da importância relativa dos produtores primários como fonte de carbono para os peixes-rei serão avaliadas a partir do programa IsoSource (Phillips \& Gregg 2003, Parnell et al. 2010). As relações entre a assinatura isotópica dos organismos (animais e plantas) agrupados por local e período (e tamanho do indivíduo, quando disponível) serão examinadas utilizando a análise discriminante, de acordo com McArthur \& Moorhead (1996).

\section{ANÁLISE E DISCUSSÃO DOS RESULTADOS}

Foram examinados 80 indivíduos da espécie Polidactylus virginicus, conhecido localmente como barbudo, capturados no período de março de 2013 a março de 2016. Esse período abordou meses chuvosos e secos, informação essencial para evidenciarmos mudanças temporais na dieta. Diferente do período seco, o período chuvoso obteve maior abundância de 
indivíduos, estando este fato relacionado a quantidade de macroalgas existentes no local, que esta associada diretamente com a alimentação dos indivíduos, já que espécies de peixes juvenis utilizam as macroalgas como fonte de alimentação e abrigo. Apenas 10 tubos digestivos vazio de $P$. virginicus foram constatados. Foram identificados 12 itens alimentares (Tabela1), com predomínio de Amphipoda e Fragmentos de Crustacea, com frequência de ocorrência de $41.58 \%$ e $40.72 \%$ respectivamente. Outro item que pode ser destacado é Decapoda (Dendobranchiata) com $14.92 \%$ de frequência.

Menezes \& Fiqueiredo (1985), ressaltam que a carne das espécies de peixe da família Polynemidae, são de boa qualidade, porem não são utilizados para consumo frequente. A partir disso, percebemos que a falta de pesquisas sobre essa espécie pode estar se dando pelo fato da mesma não ser de importância para o comercio. Não obstante a este fato, a espécie tem importância ecológica por participar das cadeias alimentares locais, seja como consumidora de itens como crustáceos, ou como presa para a dieta de outros peixes.

Tabela 1: Principais itens alimentares analisados para a espécie de P. virginicus ocorrentes na Ilha de Itaparica.

\begin{tabular}{|l|c|c|c|}
\hline Item & VO $\%$ & FO $\%$ & Índice Alimentar (lai) \\
\hline Amphipoda & 0.36 & 0.34 & $41.58 \%$ \\
\hline Fragmento de Crustacea & 0.33 & 0.35 & $40.72 \%$ \\
\hline Decapoda (Dendobranchiata) & 0.13 & 0.34 & $14.92 \%$ \\
\hline Material vegetal & 0.02 & 0.17 & $1.36 \%$ \\
\hline Material animal digerido & 0.02 & 0.06 & $0.38 \%$ \\
\hline Larva de Decapoda & 0.04 & 0.03 & $0.35 \%$ \\
\hline Teleostei & 0.07 & 0.01 & $0.33 \%$ \\
\hline Brachyura & 0.02 & 0.04 & $0.24 \%$ \\
\hline Mysidaceae & 0.01 & 0.03 & $0.05 \%$ \\
\hline Larva Megalopa de Brachyura & 0.01 & 0.01 & $0.05 \%$ \\
\hline Isopoda & 0.00 & 0.01 & $0.01 \%$ \\
\hline Polychaeta & 0.00 & 0.01 & $0.01 \%$ \\
\hline
\end{tabular}

Legenda 1: Análise qualitativa compreendendo o Item alimentar analisado com o seu volume (VO\%) e frequência de ocorrência (FO\%) respectivamente combinados com o índice alimentar (Iai).

\section{CONCIDERAÇÕES FINAIS}

De acordo com os resultados pode-se concluir que Polidactylus virginicus é um peixe bentívoro, com uma grande diversidade nos itens alimentares, principalmente crustáceos. Foram registradas algumas modificações morfológicas, como a presença de barbilhões e a região ventral achatada que corroboram o hábito alimentar da espécie. Foi registrado também que além de carnívoro, $P$. virginicus é generalista, não tendo uma fonte única de obtenção de alimentos, utilizando diversos itens como fonte de alimentos a partir da sua tática alimentar e capacidade de digestão (Gerking, 1994). Este fato condiz com os itens alimentares encontrados nos tubos digestivos analisados, que são principalmente crustáceos, predominantemente bentônicos e de ampla ocorrência no substrato. Este trabalho indicou também que existe uma real necessidade de pesquisas sobre a dieta e outros aspetos da biologia e ecologia de Polydactilus virginicus. 


\section{REFERÊNCIAS}

BAHIATURSA (1997). Guia de Ecoturismo da Bahia Brasil. Salvador: Governo do Estado da Bahia Secretaria da Cultura e turismo. 64p.

FIGUEIREDO, J.L. \& MENEZES, N.A. 1980. Manual de peixes marinhos do sudeste do Brasil. Museu de Zoologia, Universidade de São Paulo. São Paulo, VOL. 3.

GERKING, S.D. Feeding ecology of fish. Califórnia: Academic Press, 1994.

MACARTHUR JV \& MOOREHEAD KK (1996). Characterization of riparian species and stream detritus using multiple stable isotopes. Oecologia 107: 232-238.

MCLACHLAN A \& BROWN AC (2006). The Ecology of Sandy Shores. 2a ed. Academic Press. 373p.

MENEZES, N.A. \& FIGUEIREDO, J.L. 1985. Manual de peixes marinhos do sudeste do Brasil. V. Teleostei (4). São Paulo: Museu de Zoologia da Universidade de São Paulo. 1-105p PARNELL AC, INGER R, BEARHOP S \& JACKSON AL (2010). Source partioning using stable isotopes: coping with too much variation. PLoS ONE 5 (3), e9672.

POST DM (2002). Using stable isotopes to estimate trophic position: models, methods and assumptions. Ecology 83: 703-718.

PHILLIPS DL, GREGG JW (2003). Source partitioning using stable isotopes: coping with too many sources. Oecologia 136:261-269.

JONAS DE ANDRADE SANTOS, J. A.; Moraes, L. E.; Santos, E. P. \&amp; Santos, A. C. A. 2015. COMPOSIÇÃO DAICTIOFAUNA DE TRÊS PRAIAS NA ILHA DE ITAPARICA, BAÍA DE TODOS OS SANTOS (BAHIA: BRASIL).In: Anais do XXI Encontro Brasileiro de Ictiologia.1(1): 296-296. 